\title{
Stock Return Predictability in South Africa: The Role of Major Developed Markets
}

\author{
Yi-Chieh Wen ${ }^{\text {a }}$, Teng Lin ${ }^{\text {b, c }}$, Bin $\operatorname{Li}^{{ }^{d}}{ }^{*}$, Eduardo Roca ${ }^{d}$ \\ ${ }^{a}$ Department of Accountancy, National Cheng Kung University, Tainan, Taiwan \\ ${ }^{b}$ Institute for Financial and Accounting Studies, Xiamen University, China \\ ${ }^{c}$ Business School, Shantou University, China \\ ${ }^{d}$ Griffith Business School, Griffith University, Nathan, QLD 4111, Australia
}

\begin{abstract}
We examine stock return predictability of the South African (SA) market using lagged country monthly returns of the US, the UK, Germany, and Japan during the period from January 1973 to December 2014. Our results show that SA market return and industry returns can be significantly predicted by lagged US market return and industry returns, mainly in the pre-1996 market change period. Lagged German and Japanese returns have no predictive ability, while lagged UK returns only provide some degree of predictive power. However, the weaker return predictability for SA stock market in the post-1996 period could be due to liquidity effects of economic reforms, regulatory changes and an enhanced information environment on the SA market.
\end{abstract}

Keywords: Return predictability, Lagged US returns, Return correlation, Diversification JEL Classification: G15

* Corresponding author: Department of Accounting, Finance and Economics, Griffith Business School, Griffith University, Queensland 4111, Australia. E-mail: b.li@griffith.edu.au; Tel: +61 7373 57117. 


\section{Introduction}

Empirical research in international finance has shifted the attention to cross-country stock return predictability and correlations (e.g., Longin, and Solnik, 2001; Rapach et al., 2005; Hjalmarsson, 2010). These studies point out that only a small number of macroeconomic or financial variables (e.g., interest rates, inflation rate, and dividend yields) can be regarded as useful indicators for predicting stock returns. However, given the inconsistent empirical results of these studies, no specific variables are yet able to provide exhaustive explanations for the variations of stock returns across countries.

More recently, two studies show that the US plays a leading role in the global stock markets. For example, Rapach et al. (2013) explore lead-lag relationships among country stock returns and demonstrate that lagged US returns can predict stock returns in many nonUS countries better than their domestic economic variables ${ }^{1}$. Bollerslev et al. (2013) find that the global variance risk premium, with the US market having more than 60 percent of the weight, serves as a stronger predictor of the future returns of non-US countries as compared to the respective individual country risk premiums. Similarly, the leading role of the US in international equity markets has been emphasized in a number of other studies (e.g., Eun and Shim, 1989; Bessler and Yang, 2003). These studies elucidate the gradual information diffusion from the US market into the markets of other countries. Thus, for many non-US countries, the return linkages with the US equity markets can capture an important source of international return predictability.

In this paper, we investigate the stock return predictability for the South African (SA) market using lagged country returns of the US, the UK, Germany, and Japan, in the spirit of

\footnotetext{
${ }^{1}$ Campbell and Hamao (1992) emphasize that a specific variable which has predictive power for international equity returns seems to express a common stock market component. In particular, stock prices are available on a continuous basis with no informational lag (Estrella and Mishkin, 1998) and reflect much information from the combination of environmental conditions and the number of market participants (Lo, 2004).
} 
Rapach et al. (2013). As documented by Masih and Masih (1997, 1999), developed stock markets such as the US, the UK, Germany, and Japan can influence other regional stock market fluctuations like those of Taiwan, South Korea, Singapore, and Hong Kong. Previous research provides very little evidence of return predictability in the SA stock market ${ }^{2}$. The SA capital market has witnessed remarkable changes during the decade of the 1990s arising most notably from the unification of the dual exchange rate regime in March of 1995 and the introduction of the new Stock Exchange Control Act in November of 1995. These reforms have affected its capital market and led to a significant change in its correlation with international stock markets. Thus, we consider the potential impact of these reforms in the SA stock market by dividing our sample into the pre-1996 and post-1996 change periods.

The existing literature has focused on the relative importance of country (national market) and industry factors in explaining international stock returns, implying return comovements and international portfolio diversification. Some prior studies find that crosscountry diversification presents greater risk reduction than cross-industry diversification (e.g., Griffin and Karolyi, 1998; Rouwenhorst, 1999). Others show that industry compositions play a determinant role in explaining market returns (Roll, 1992) and industry effects have gradually overtaken country effects (e.g., Cavaglia et al., 2000; Ferreira and Gama, 2010). We argue that the different industries that compose the SA market will have different predictive relationships with world market returns.

We examines the return predictability of the SA stock market across 30 industries using the lagged country returns of the US, the UK, Germany, and Japan over the period January 1973 to December 2014. Our results show that SA market industry returns could be significantly predicted by lagged US returns (including market return and the corresponding

\footnotetext{
${ }^{2}$ We focus on South Africa's linkages with the US, the UK, Japan and Germany because these countries are the most important partners of South Africa in terms of trade (import or export) and investments. Moreover, South African Reserve Bank (SARB) surveys indicate that the UK, the US, Germany and Japan have become the major sources of Foreign direct investment (FDI) in SA during the past decade.
} 
industry returns), only in the pre-1996 period. However, lagged German and Japan returns do not affect SA industry returns while lagged UK returns provide only some degree of predictive ability. The weak return predictability in the post-1996 period arises from the financial market liberalization, which has changed aspects of market efficiency and the liquidity.

Our paper makes three primary contributions to the literature. First, as suggested by Gupta and Modise (2012, 2013), macroeconomic and financial variables seem to contain less predictive information for SA stock returns. We use lagged country returns and emphasize the "common and best" predictor at the international level. Our main result, especially in the pre-1996 period, is consistent with that of Rapach et al. (2013). Second, we explore the predictability of industry portfolio returns and find that US industry returns can predict crossmarket returns within certain similar industries. Our study also sheds light on the potentially important issue for industry factors in explaining international return variations.

Finally, our findings imply the evolving characteristics of the SA stock market from the gradual influences of economic reforms and reflect the international capital mobility. Several studies also provide some insight into the potential impacts of our results by combining environmental conditions and the number of market participants. Hong and Stein (1999) indicate that gradual information diffusion among investors can explain stock return predictability. Menzly and Ozbas (2010) find that the degree of return predictability across markets declines with the number of informed investors. Cumming et al. (2011) document an important source of information from stock exchange trading rules to explain international differences in market liquidity (such as velocity, volatility, and bid-ask spread). They also show that exchange surveillance and information sharing facilitate market efficiency and integrity. 
The remainder of this paper is organized as follows. Section 2 outlines the data and methodology. Section 3 presents the empirical findings. Section 4 concludes.

\section{Data and Methodology}

\subsection{Data}

Our data set comprises the monthly market return indices of SA and MSCI total return data for four developed markets - the US, the UK, Germany, and Japan, covering the period from January 1973 to December 2014. All data are collected from DataStream. The monthly stock returns are calculated using daily price indices. To analyze the predictability of industry returns between SA and the US, we construct industry portfolios from DataStream constituent stocks of Industry Classification Benchmark (ICB) level 4 groups. We obtain 30 industry portfolio returns that are available and common to both the US and South Africa.

The summary statistics of the monthly SA industry returns and market total returns for SA, the US, the UK, Germany (GE), and Japan (JP) are presented in Table 1. The mean returns vary across industries with the largest of at $2.59 \%$ per month for the Pharmaceuticals \& Biotechnology industry (ind 16) and the lowest of at $0.40 \%$ per month for the Travel \& Leisure industry (ind 20). The Equity Investment Instruments industry (ind 29) is the most volatile, with the highest standard deviation of 16.83\%, whereas the Real Estate Investment \& Service industry (ind 26) has the lowest standard deviation of 3.75\%. Most return series are left skewed and leptokurtic. The Jacque-Bera normality test results also show the rejection of the null hypothesis at the $1 \%$ significance levels for most industries. The firstorder autocorrelation coefficients vary across industries, but most of them are less than 0.1 . In terms of market returns, the US market has higher mean returns $(0.95 \%)$ and seems to be more volatile $($ Std. Dev. $=5.49 \%)$ than other countries.

\subsection{Methodology}


This paper uses a predictive regression framework to analyze the stock return predictability of the SA market. We run the following regression equations (at the market level):

$$
\begin{aligned}
& R_{S A, t+1}^{M}=\alpha+\beta R_{S A, t}^{M}+\gamma R_{\text {Other }, t}^{M}+\varepsilon_{t+1} \\
& R_{S A, t+1}^{M}=\alpha+\beta R_{S A, t}^{M}+\gamma R_{\text {Other }, t}^{M}+\kappa R_{\text {Other }, t}^{M} * D^{\prime} m_{t}+\varepsilon_{t+1}
\end{aligned}
$$

where $R_{S A, t+1}^{M}$ is the one-month ahead monthly market return of SA; $R_{\text {Other }, t}^{M}$ is returns on other stock markets including the US $\left(R_{U S, t}^{M}\right)$, the UK $\left(R_{U K, t}^{M}\right)$, Germany $\left(R_{G E, t}^{M}\right)$, and Japan $\left(R_{J P, t}^{M}\right)$ in month $t$, and $\varepsilon_{t+1}$ is an error term. In addition, we include a dummy variable (Dum $\left.t\right)$ in Eq. (2) to control the predictive effect between the pre-1996 and post-1996 stock market change periods. The coefficient of interaction term $\left(R_{\text {Other, }}^{M} * D_{u m}\right)$ captures the change in the effect of other markets on the SA market in the post-1996 period, compared to the earlier period.

On the other hand, as mentioned earlier, industry compositions or returns play a crucial role in explaining stock market returns (Roll, 1992; Chou et al., 2012). Moreover, Rapach et al. (2013) provide evidence that the US stock market is the leader amongst world markets and also confirm the predictive ability of lagged US returns. We thus compare the predictability of common industry groups between the SA market and the US market using lagged US industry returns ( $R_{i, t}^{U S}$ ). We apply alternative specifications of the regression equations by replacing lagged country returns with lagged US industry returns as a predictor. The regression equations (at the industry level) are:

$$
\begin{aligned}
& R_{i, t+1}^{S A}=\alpha_{i}+\beta_{i} R_{i, t}^{S A}+\gamma_{i} R_{i, t}^{U S}+\varepsilon_{i, t+1} \\
& R_{i, t+1}^{S A}=\alpha_{i}+\beta_{i} R_{i, t}^{S A}+\gamma_{i} R_{i, t}^{U S}+\kappa_{i} R_{i, t}^{U S} * \operatorname{Dum}_{t}+\varepsilon_{i, t+1}
\end{aligned}
$$

where $R_{i, t+1}^{S A}$ is the one-month ahead return on industry $i$ in SA; $R_{i, t}^{U S}$ is US industry returns that correspond and are common to the SA industry portfolios in month $t$. We also consider the 
impact of SA market change periods and use a dummy variable (Dum) in Eq. (4). Finally, we use the Newey-West procedure with 6 lags to correct for the heterogeneous and autocorrelation issues in standard errors.

\section{Empirical Results}

\subsection{Market Level Analysis of Return Predictor}

We examine return predictability for the SA stock market using lagged country returns $\left(R_{O \text { ther,t }}^{M}\right)$ of the US $\left(R_{U S, t}^{M}\right)$, the UK $\left(R_{U K, t}^{M}\right)$, Germany $\left(R_{G E, t}^{M}\right)$, and Japan $\left(R_{J P, t}^{M}\right)$ during the period from January 1973 to December 2014. Table 2 presents the results of return predictability at market (country) level. We perform the full sample and subsample (the pre1996 and post-1996 periods) analyses. Also, the relationship is examined by adding an interaction term between lagged country returns $\left(R_{\text {Other, }}^{M}\right)$ and Dum $t_{t}$ to capture the impact of the economic reforms on the SA market.

The empirical results show that the lagged US market return, compared to other lagged country returns in the full sample, has greater predictive power (significant at the 5\% level). There is only limited evidence of predictability for SA market return using the lagged UK market return. The lagged German and Japanese returns have no impact on SA market return. Further, when including the interaction term $\left(R_{\text {Other, }}^{M} * D u m_{t}\right)$ in the regression model, the return predictability of all developed stock markets are not statistically significant in the post-1996 period. We find weak evidence of predictability for the SA market return using lagged country returns in both sub-periods. However, lagged US market return is still shown to have the strongest predictive ability for the SA market return in the pre-1996 period. The coefficient of the lagged US market return is 0.222 , indicating that a one percent increase in the US market return will push up the SA market return by 22 basis points in the next month. Though the coefficient of the interaction term (US market) is not significant, it is negative 
(close to -0.1), implying that there might be a reduction in the effect of the lagged US market return in the post-1996 period.

Moreover, we report the results of predictability for the SA market return including two different periods. The first sub-sample period (1973 to 1995) indicates the phase before the market changes took effect in relation to the unification of the dual exchange rate regime and the removal of exchange controls. The second sub-sample period is the integration and improvement phase of stock market between 1996 and 2014. In terms of the US market, the predictive power of SA market return using lagged US market return has attenuated over time, particularly in the post-1996 period (the significant coefficient of 0.187 , at the $10 \%$ level only). One possible interpretation of this result is that the stock market reflects the predictive shifts from financial capital mobility or market liquidity due to the changes in the economic and information environment. Stock market liquidity can affect expected stock returns where an increase in liquidity reduces the stock premium or leads to lower subsequent returns (Bekaert et al., 2007; Assefa and Mollick, 2014).

\section{[Table 2 about here]}

The market return of a country as a whole includes the returns from various industries. The role of industry returns has been emphasized in previous studies (e.g., Roll, 1992; Hong et al., 2007). Stock market returns may be driven by industry-related patterns. Thus, we further investigate whether lagged country returns can predict SA industry returns. According to the results of the full sample shown in Table 2, we find two significant predictors including the lagged US and UK market returns ${ }^{3}$. However, we only examine US market because Rapach et al. (2013) document that lagged US market return serves as a stronger predictor for

\footnotetext{
${ }^{3}$ For brevity and clarity, we do not report the results for the UK, German and Japanese stock markets because they provide limited predictability or have no significant effects on SA market returns.
} 
many non-US returns. Moreover, we control the impact of SA market changes due to the ending of apartheid and the removal of sanctions in 1995.

We find that lagged US market return is regarded as a powerful predictor when it significantly forecasts 10 industry returns (at the 5\% level) of SA market in the pre-1996 period, as shown in Table 3. All the coefficients except the one for Real Estate Investment Trusts (ind27) ${ }^{4}$ are positive, indicating that higher returns in the US market lead to higher next-month returns in those SA industries. In the post-1996 period, the coefficients of the interaction term of 6 industries are significantly negative at the $5 \%$ level, implying a weakening in the predictive ability of the lagged US market return. The weaker result may reflect the influence of the increased globalization and correlation with the world economy coupled with the effects of regulatory reforms which have improved the efficiency of the SA market, making the impact from major markets such as the US more immediate rather than having a lag of one month.

\section{[Table 3 about here]}

\subsection{Industry Level Analysis of Return Predictor}

Given the global integration of various industry sectors in the world economy, industry factors have gradually dominated country factors. As argued by Chou et al. (2012), industry returns reflect both significant rational (covariance risk) and behavioral (mispricing) components, but these theoretical perspectives cannot fully explain industry returns. Hong et al. (2007) document that industry returns can predict stock market movements and economic fundamentals. However, recent research indicates that the increased importance of industry factors may be a temporary phenomenon or contagion effect from a financial crisis (Bekaert et al., 2009; Bai et al., 2012). Therefore, we examine whether US industry returns help

\footnotetext{
${ }^{4}$ The starting date for ind27 is January 1990 and thus only 6 years data are included in the pre-1996 period.
} 
predict the corresponding SA industry returns using all 30 lagged US industry returns as regressors ${ }^{5}$.

When including the interaction term between lagged US industry returns and the change periods of the pre-and post-1996 into our regression, as shown in Table 4, we find that in the pre-1996 period, 10 industries in the US market can significantly predict SA industry returns - nine at the 5\% significance level and one (Financial Services industry) at the $10 \%$ level. However, for the post-1996 period, we observe that for 3 industries in the US market (Electronic \& Electrical Equipment, Banks, and Life Insurance), the coefficients of the interaction term are negative and significant at the $5 \%$ level, which indicate that the return predictive powers have declined in the post-1996 period in comparison to the earlier period. It may well be that these industries are reflecting much more fully the changing economic and regulatory environment in SA relating to the improvement in market efficiency as well as realignment in trading arrangements as these three industries are ones that are significantly linked with the international sector and at the same time exposed heavily to the reforms implemented in SA.

In summary, our results suggest that SA stock returns in the pre-1996 market change period can be significantly predicted by lagged US market return and industry returns. The evidence here is consistent with the findings of Rapach et al. (2013) that lagged US returns are useful predictors. However, the weaker return predictability in the post-1996 period is potentially due to the fact that the market reflects the predictable shifts stemming from economic reforms, regulatory changes and the improved information environment. The economic intuition behind our results indicates the dynamics of the market liquidity. The degree of return predictability is gradual information diffusion through environmental

\footnotetext{
${ }^{5}$ Since the US market returns have been shown to be the main predictor of SA market as well industry returns, and in line with Rapach et al. (2013), we focus only on the US in terms of the effect of industry returns of other countries on the corresponding SA industry returns.
} 
conditions and the number of market participants (Hong and Stein, 1999; Menzly and Ozbas, 2010). As document by Cumming et al. (2011), differences in the trading rules of each stock exchange significantly affect liquidity over time and across markets.

\section{Conclusions}

This research, which is motivated by Roll (1992), Hong et al. (2007), and Rapach et al. (2013), seeks to bridge the gap in the literature by examining the predictive relationship between the lagged country returns and the SA industry returns. We investigate stock returns predictability for the SA market using lagged country monthly returns of the US, the UK, Germany, and Japan over the period January 1973 to December 2014. We find that SA market return and industry returns could be significantly predicted by lagged US returns (including market return and the corresponding industry returns), only in the pre-1996 period. Lagged German and Japan returns do not affect SA market return while lagged UK returns provide limited predictive ability. However, one possible explanation for the relative weakness of return predictability in the post-1996 period may come from economic development, regulatory changes and the improved information environment in South Africa.

The empirical results presented in this paper have several implications with regard to return predictability. For investors, they may have the possibility of gaining risk reduction through international portfolio diversification. For policy makers, the predictive ability of stock returns can help detect financial capital mobility. For academic researchers, although many potential indicators can be employed to predict future stock returns, we attempt to seek the "common and best" predictor in the global equity markets. Our results also open up possible avenues for future research into the economic consequences and practical trading strategies of lead-lag predictive relationships based on industry portfolios. 


\section{References}

Assefa, T.A., Mollick, A.V., 2014. African stock market returns and liquidity premia. Journal of International Financial Markets, Institutions and Money 32, 325-342.

Bai, Y., Green, C.J., Leger, L., 2012. Industry and country factors in emerging market returns: Did the Asian crisis make a difference? Emerging Markets Review 13, 559-580.

Bekaert, G., Harvvey, C.R., Christian, L., 2007. Liquidity and expected returns: lessons from emerging markets. Review of Financial Studies 20 (5), 1783-1831.

Bekaert, G., Engstrom, E., Xing, Y., 2009. Risk, uncertainty, and asset prices. Journal of Financial Economics 91, 59-82.

Bessler, D.A., Yang, J., 2003. The structure of interdependence in international stock markets. Journal of International Money and Finance 22, 261-287.

Bollerslev, T., Marrone, J., Xu, L., Zhou, H., 2013. Stock return predictability and variance risk premia: Statistical inference and international evidence. Journal of Financial and Quantitative Analysis 49 (3), 633-661.

Campbell, J.Y., Hamao, Y. 1992. Predictable stock returns in the United States and Japan: A study of long-term capital market integration. Journal of Finance 47, 43-69.

Cavaglia, S., Brightman, C., Aked, M., 2000. The increasing importance of industry factors. Financial Analysts Journal 56 (5), 41-54.

Chou, P.H., Ho, P.H., Ko, K.C., 2012. Do industries matter in explaining stock returns and asset-pricing anomalies? Journal of Banking and Finance 36, 355-370.

Cumming, D., Johan, S., Li, D., 2011. Exchange trading rules and stock market liquidity. Journal of Financial Economics 99 (3), 651-671

Estrella, A., Mishkin, F. S., 1998. Predicting U.S. recessions: Financial variables as leading indicators. Review of Economics and Statistics 80 (1), 45-61.

Eun, C., Shim, S., 1989. International transmission of stock market movements. Journal of Financial and Quantitative Analysis 24, 241-256.

Ferreira, M.A., Gama, P.M., 2010. Correlation dynamics of global industry portfolios. Journal of Multinational Financial Management 20, 35-47.

Griffin, J.M., Karolyi, G.A., 1998. Another look at the role of the industrial structure of markets for international diversification strategies. Journal of Financial Economics 50, 351-373. 
Gupta, R., Modise, M.P., 2012. South African stock return predictability in the context data mining: The role of financial variables and international stock returns. Economic Modelling 29, 908-916.

Gupta, R., Modise, M.P., 2013. Macroeconomic variables and South African stock return predictability. Economic Modelling 30, 612-622.

Hjalmarsson, E., 2010. Predicting global stock returns. Journal of Financial and Quantitative Analysis 45, 49-80.

Hong, H., Stein, J.C., 1999. A unified theory of underreaction, momentum trading, and overreaction in asset markets. Journal of Finance 54 (6), 2143-2184.

Hong, H., Torous, W., Valkanov, R., 2007. Do industries lead stock markets? Journal of Financial Economics 83 (2), 367-396.

Lo, A. W., 2004. The adaptive markets hypothesis: market efficiency from an evolutionary perspective. Journal of Portfolio Management 30, 15-29.

Longin, F., Solnik, B., 2001. Extreme correlation in international equity markets. Journal of Finance 56, 649-676.

Masih, A.M.M., Masih, R., 1997. Dynamic linkages and the propagation mechanic driving major international markets: an analysis of the pre- and post-crash eras. Quarterly Review of Economics and Finance 37 (4), 859-885.

Masih, A.M.M., Masih, R., 1999. Are Asian stock market fluctuations due mainly to intraregional contagion effects? Evidence based on Asian emerging stock markets. PacificBasin Finance Journal 7, 251-282.

Menzly, L., Ozbas, O., 2010. Market segmentation and cross-predictability of returns. The Journal of Finance 65(4), 1555-1580.

Rapach, D., Wohar, M.E., Rangvid, J., 2005. Macro variables and international stock return predictability. International Journal of Forecasting 21, 137-166.

Rapach, D., Strauss, J.K., Zhou, G., 2013. International stock return predictability: What is the role of the United States? Journal of Finance 68 (4), 1633-1662.

Roll, R., 1992. Industrial structure and the comparative behavior of international stock market indices. Journal of Finance 47 (1), 3-41.

Rouwenhorst, G.K., 1999. Local return factors and turnover in emerging stock markets. Journal of Finance 54 (4), 1439-1464. 
Table1

Summary statistics

\begin{tabular}{|c|c|c|c|c|c|c|c|c|c|}
\hline Code & Industry/Country & Mean & Median & $\begin{array}{l}\text { Std. } \\
\text { Dev. }\end{array}$ & Skewness & Kurtosis & $\begin{array}{l}\text { Jacque- } \\
\text { Bera }\end{array}$ & $\rho(1)$ & $\begin{array}{c}\text { Sample } \\
\text { starting date }\end{array}$ \\
\hline ind1 & Oil \& Gas Producers & 1.51 & 1.23 & 8.60 & -0.18 & 1.52 & 43.01 & 0.00 & Oct. 1979 \\
\hline ind2 & Chemicals & 1.14 & 1.60 & 9.09 & -0.83 & 6.53 & 954.91 & 0.09 & Jan. 1973 \\
\hline ind3 & Forestry \& Paper & 1.14 & 1.47 & 10.69 & -0.12 & 2.49 & 131.06 & 0.01 & Jan. 1973 \\
\hline ind4 & Industrial Metals \& Mining & 0.81 & 1.40 & 14.86 & -2.76 & 24.47 & 7840.60 & -0.10 & Jan. 1990 \\
\hline ind5 & Mining & 1.22 & 1.34 & 8.58 & -0.43 & 1.13 & 41.92 & 0.03 & Jan. 1973 \\
\hline ind6 & Construction \& Materials & 1.05 & 1.37 & 8.56 & -0.22 & 1.45 & 25.33 & 0.07 & Nov. 1992 \\
\hline ind7 & General Industrials & 1.44 & 1.60 & 7.61 & -2.16 & 17.14 & 6564.14 & 0.01 & Jan. 1973 \\
\hline ind8 & Electronic \& Electrical Equipment & 1.01 & 0.66 & 11.19 & -1.70 & 15.27 & 2468.37 & 0.10 & Oct. 1994 \\
\hline ind9 & Industrial Transportation & 1.67 & 0.00 & 13.63 & 0.55 & 7.77 & 766.30 & -0.10 & Jan. 1990 \\
\hline ind10 & Support Services & 1.16 & 0.13 & 6.33 & -0.43 & 1.54 & 40.48 & 0.04 & Jan. 1989 \\
\hline ind11 & Beverages & 1.61 & 1.58 & 7.90 & 0.21 & 1.39 & 26.36 & 0.01 & Jan. 1990 \\
\hline ind12 & Food Producers & 1.48 & 1.31 & 6.28 & -0.34 & 1.42 & 51.94 & 0.08 & Jan. 1973 \\
\hline ind13 & $\begin{array}{l}\text { Household Goods \& Home } \\
\text { Construction }\end{array}$ & 1.40 & 1.35 & 9.14 & -0.38 & 1.25 & 17.39 & 0.03 & Sep. 1998 \\
\hline ind14 & Leisure Goods & 1.17 & 0.00 & 9.46 & -0.65 & 12.61 & 2001.51 & 0.02 & Jan. 1990 \\
\hline ind15 & Health Care Equipment \& Services & 1.88 & 1.93 & 8.63 & -0.35 & 3.83 & 188.94 & 0.04 & Jan. 1990 \\
\hline ind16 & Pharmaceuticals \& Biotechnology & 2.59 & 1.22 & 15.41 & 2.41 & 16.45 & 3511.92 & -0.05 & Jan. 1991 \\
\hline ind17 & Food \& Drug Retailers & 1.51 & 2.07 & 7.70 & -0.71 & 2.38 & 71.87 & -0.09 & Apr. 1996 \\
\hline ind18 & Gen Retailers & 1.08 & 2.07 & 11.81 & -5.46 & 63.21 & 51269.92 & 0.06 & Jan. 1990 \\
\hline ind19 & Media & 1.79 & 2.51 & 10.02 & -0.74 & 2.46 & 76.90 & 0.13 & Mar. 1996 \\
\hline ind20 & Travel \& Leisure & 0.40 & 0.45 & 11.09 & -0.79 & 6.27 & 473.18 & -0.01 & Apr.1992 \\
\hline ind21 & Fixed Line Telecommunications & 1.56 & 1.96 & 8.37 & -0.39 & 0.75 & 6.79 & 0.12 & Mar. 2003 \\
\hline ind22 & Mobile Telecommunications & 1.98 & 1.74 & 10.88 & -1.22 & 9.80 & 964.43 & 0.02 & Jan. 1996 \\
\hline ind23 & Banks & 1.64 & 1.61 & 7.08 & -1.29 & 10.57 & 1668.83 & 0.01 & Oct. 1986 \\
\hline ind24 & Nonlife Insurance & 1.85 & 1.97 & 7.75 & -0.70 & 8.53 & 1042.55 & 0.10 & Jan. 1987 \\
\hline ind25 & Life Insurance & 1.49 & 1.49 & 7.54 & -0.45 & 2.85 & 187.20 & 0.03 & Jan. 1973 \\
\hline ind26 & Real Estate Investment \& Services & 2.01 & 0.97 & 3.75 & 0.40 & -1.17 & 1.16 & 0.06 & Oct. 2013 \\
\hline ind27 & Real Estate Investment Trusts & 1.50 & 1.59 & 7.04 & -0.32 & 2.60 & 89.74 & -0.05 & Jan. 1990 \\
\hline ind28 & Financial Services & 1.85 & 1.80 & 7.97 & -1.12 & 9.39 & 1162.39 & 0.03 & Jan. 1990 \\
\hline ind29 & Equity Investment Instruments & 1.54 & 0.00 & 16.83 & 0.42 & 9.74 & 1190.25 & 0.23 & Jan. 1990 \\
\hline ind30 & Technology Hardware \& Equipment & 0.87 & 0.00 & 8.00 & 0.68 & 3.83 & 206.26 & -0.03 & Jan. 1990 \\
\hline SA & South African market & 0.84 & 1.19 & 4.50 & -0.71 & 2.63 & 188.49 & 0.03 & Jan. 1973 \\
\hline US & United States market & 0.95 & 1.39 & 5.49 & 0.21 & 9.03 & 1715.58 & 0.06 & Jan. 1973 \\
\hline UK & United Kingdom market & 0.67 & 1.05 & 5.15 & -0.87 & 2.91 & 241.77 & 0.09 & Jan. 1973 \\
\hline GE & German market & 0.41 & 0.58 & 5.16 & -0.39 & 1.65 & 70.32 & 0.09 & Jan. 1973 \\
\hline JP & Japanese market & 0.84 & 1.19 & 4.51 & -0.71 & 2.62 & 188.48 & 0.11 & Jan. 1973 \\
\hline
\end{tabular}

Notes: Industry and country (market) monthly data cover the period from January 1973 to December 2014. This table presents summary statistics for 30 SA industry returns and the market returns for South Africa, the US, the UK, Germany and Japan. The returns are expressed as a percentage. Sample starting date is the first date (month) of available data from DataStream. Industry portfolio returns are classified based on DataStream Industry Level 4 sectors. 
Table 2

The predictive relationship between one-month ahead SA market return and lagged country returns

\begin{tabular}{|c|c|c|c|c|c|c|c|c|c|}
\hline Markets & const & t-stat & $R_{i, t}$ & t-stat & $R_{\text {other, }}$ & t-stat & $R_{\text {other }, t} *$ Dum & t-stat & $\mathrm{R}^{2}$ \\
\hline \multicolumn{10}{|c|}{ Full sample: Jan 1973- Dec 2014} \\
\hline$\overline{\text { US }}$ & $0.014 * *$ & $(4.57)$ & -0.028 & $(-0.59)$ & $0.179 * *$ & $(2.87)$ & & & 0.009 \\
\hline UK & $0.014^{* *}$ & (4.64) & -0.003 & $(-0.06)$ & 0.091* & (1.93) & & & 0.002 \\
\hline Germany & $0.014 * *$ & $(4.76)$ & 0.002 & $(0.04)$ & 0.079 & (1.14) & & & 0.000 \\
\hline Japan & $0.014 * *$ & (4.83) & 0.016 & $(0.33)$ & 0.036 & $(0.60)$ & & & -0.003 \\
\hline \multicolumn{10}{|c|}{ Full sample with dummy: Jan 1973- Dec 2014} \\
\hline US & $0.014 * *$ & $(4.56)$ & -0.025 & $(-0.53)$ & $0.222 * *$ & $(2.56)$ & -0.095 & $(-0.87)$ & 0.008 \\
\hline UK & $0.014 * *$ & $(4.66)$ & -0.009 & $(-0.18)$ & 0.075 & (1.62) & 0.074 & $(0.72)$ & 0.000 \\
\hline Germany & $0.014 * *$ & $(4.75)$ & 0.002 & $(0.04)$ & 0.075 & $(0.65)$ & 0.007 & $(0.05)$ & -0.002 \\
\hline Japan & $0.014 * *$ & $(4.81)$ & 0.015 & $(0.31)$ & 0.025 & $(0.31)$ & 0.027 & $(0.24)$ & -0.005 \\
\hline \multicolumn{10}{|c|}{ Pre-1996 sample: Jan 1973- Dec 1995} \\
\hline US & $0.015^{* *}$ & $(3.31)$ & 0.000 & $(-0.00)$ & $0.199 * *$ & $(2.27)$ & & & 0.008 \\
\hline UK & $0.016^{* *}$ & (3.41) & 0.026 & $(0.42)$ & 0.057 & $(1.16)$ & & & -0.003 \\
\hline Germany & $0.016 * *$ & (3.48) & 0.030 & $(0.50)$ & 0.055 & $(0.47)$ & & & -0.004 \\
\hline Japan & $0.016 * *$ & $(3.50)$ & 0.039 & $(0.65)$ & 0.005 & $(0.06)$ & & & -0.006 \\
\hline \multicolumn{10}{|c|}{ Post-1996 sample: Jan 1996- Dec 2014} \\
\hline$\overline{\text { US }}$ & $0.012 * *$ & (3.27) & -0.095 & $(-1.18)$ & 0.187* & $(1.87)$ & & & 0.006 \\
\hline UK & $0.012 * *$ & $(3.36)$ & $-0.109 *$ & $(-1.90)$ & $0.242^{* *}$ & $(2.37)$ & & & 0.011 \\
\hline Germany & $0.012^{* *}$ & (3.37) & -0.068 & $(-1.14)$ & 0.124* & (1.77) & & & 0.002 \\
\hline Japan & $0.013^{* *}$ & (3.54) & -0.049 & $(-0.85)$ & 0.097 & (1.11) & & & -0.003 \\
\hline
\end{tabular}

Notes: Regression equation: $R_{S A, t+1}^{M}=\alpha+\beta R_{S A, t}^{M}+\gamma R_{\text {other, } t}^{M}+\kappa R_{\text {other, },}^{M} * D u m_{t}+\varepsilon_{t+1}$, where $R_{S A, t+1}^{M}$ is one-month ahead market return of $\mathrm{SA}$, and $R_{\text {Other, }}^{M}$ is lagged monthly returns on other stock markets including the US $\left(R_{U S, t}^{M}\right)$, the UK $\left(R_{U K, t}^{M}\right)$, Germany $\left(R_{G E, t}^{M}\right)$, and Japan $\left(R_{J P, t}^{M}\right)$. Dum is a dummy variable which equals 0 if the observation is prior to year 1996 and 1 otherwise. We also split the sample into two sub-sample periods: the pre-1996 and the post-1996 market change periods. *, **, and *** denote significance at the $10 \%, 5 \%$, and $1 \%$ levels, respectively. Significant regression coefficients are highlighted in bold. 
Table 3

Predictability of lagged US market return on SA industry returns for the pre-and post-1996 periods

\begin{tabular}{|c|c|c|c|c|c|c|c|c|c|}
\hline Portfolio & const & t-stat & $R_{i, t}$ & t-stat & $R_{U S, t}$ & t-stat & $R_{U S, t} *$ Dum & t-stat & $\mathrm{R}^{2}$ \\
\hline ind1 & $0.013 * *$ & $(2.70)$ & -0.027 & $(-0.56)$ & 0.234 & $(1.54)$ & -0.099 & $(-0.57)$ & 0.001 \\
\hline ind2 & 0.008* & (1.66) & 0.056 & (1.11) & $0.348 * *$ & $(2.84)$ & 0.026 & $(0.10)$ & 0.033 \\
\hline ind3 & $0.009 *$ & (1.68) & -0.044 & $(-0.86)$ & $0.394^{* *}$ & (2.59) & 0.031 & $(0.12)$ & 0.021 \\
\hline ind4 & 0.009 & $(0.85)$ & -0.104 & $(-1.11)$ & -0.078 & $(-0.20)$ & 0.145 & $(0.35)$ & 0.001 \\
\hline ind5 & $0.011^{* *}$ & $(2.71)$ & 0.011 & $(0.23)$ & 0.174* & $(1.81)$ & -0.149 & $(-0.97)$ & -0.001 \\
\hline ind6 & 0.010 & (1.59) & 0.055 & (0.93) & -0.393 & $(-0.70)$ & 0.542 & $(0.95)$ & 0.001 \\
\hline ind7 & $0.013 * *$ & (3.54) & $-0.087^{*}$ & $(-1.90)$ & $0.392 * *$ & (4.19) & -0.078 & $(-0.41)$ & 0.030 \\
\hline ind8 & 0.007 & $(0.88)$ & 0.078 & $(0.78)$ & $1.267^{* *}$ & (2.93) & $-1.153^{* *}$ & $(-2.42)$ & 0.006 \\
\hline ind9 & $0.016^{* *}$ & (2.18) & -0.134 & $(-1.51)$ & 0.610 & (1.09) & -0.270 & $(-0.48)$ & 0.014 \\
\hline ind10 & $0.009 * *$ & (2.57) & -0.007 & $(-0.09)$ & $0.565^{* *}$ & $(2.47)$ & $-0.433^{* *}$ & $(-1.97)$ & 0.022 \\
\hline ind11 & $0.015^{* *}$ & $(2.91)$ & -0.005 & $(-0.09)$ & 0.231 & $(0.67)$ & -0.103 & $(-0.29)$ & -0.004 \\
\hline ind12 & $0.013 * *$ & $(4.49)$ & 0.047 & $(1.00)$ & $0.265^{* *}$ & $(3.05)$ & $-0.186^{*}$ & $(-1.65)$ & 0.021 \\
\hline ind13 & NA & & & & & & & & \\
\hline ind14 & $0.011^{* *}$ & (2.09) & 0.026 & $(0.32)$ & 0.073 & $(0.20)$ & -0.100 & $(-0.26)$ & -0.009 \\
\hline ind15 & $0.017 * *$ & (2.98) & 0.033 & $(0.32)$ & 0.492 & $(1.18)$ & -0.470 & $(-1.09)$ & 0.001 \\
\hline ind16 & $0.028 * *$ & (3.27) & -0.051 & $(-0.62)$ & -0.376 & $(-0.61)$ & 0.373 & $(0.56)$ & -0.007 \\
\hline ind17 & NA & & & & & & & & \\
\hline ind18 & 0.009 & (1.34) & $0.054 * *$ & $(2.32)$ & 0.315 & $(0.80)$ & -0.220 & $(-0.53)$ & -0.003 \\
\hline ind19 & NA & & & & & & & & \\
\hline ind20 & 0.003 & $(0.44)$ & -0.020 & $(-0.26)$ & 0.029 & $(0.05)$ & 0.067 & $(0.11)$ & -0.010 \\
\hline ind21 & NA & & & & & & & & \\
\hline ind22 & NA & & & & & & & & \\
\hline ind23 & $0.015 * *$ & $(4.34)$ & -0.032 & $(-0.72)$ & $0.431 * *$ & $(2.96)$ & $-0.336 * *$ & $(-1.98)$ & 0.015 \\
\hline ind24 & $0.015 * *$ & (3.98) & 0.014 & $(0.34)$ & $0.698 * *$ & (3.34) & $-0.461 * *$ & $(-2.21)$ & 0.053 \\
\hline ind25 & $0.013 * *$ & $(4.05)$ & -0.022 & $(-0.41)$ & $0.369 * *$ & (3.31) & $-0.324^{* *}$ & $(-2.44)$ & 0.019 \\
\hline ind26 & NA & & & & & & & & \\
\hline ind27 & $0.017 * *$ & $(3.72)$ & -0.057 & $(-0.88)$ & $-0.301 * *$ & $(-1.97)$ & $0.348^{*}$ & $(1.76)$ & -0.001 \\
\hline ind28 & $0.016 * *$ & (3.66) & -0.030 & $(-0.48)$ & $0.613^{*}$ & $(1.86)$ & -0.417 & $(-1.27)$ & 0.013 \\
\hline ind29 & 0.012 & (1.19) & $0.206^{* *}$ & $(2.64)$ & -0.509 & $(-1.09)$ & $0.943^{* *}$ & $(2.00)$ & 0.054 \\
\hline Ind30 & 0.007 & (1.55) & -0.051 & $(-0.60)$ & 0.244 & $(1.42)$ & 0.001 & $(0.01)$ & 0.008 \\
\hline
\end{tabular}

Notes: Regression equation: $R_{i, t+1}^{S A}=\alpha_{i}+\beta_{i} R_{i, t}^{S A}+\gamma_{i} R_{U S, t}^{M}+\kappa_{i} R_{U S, t}^{M} * D u m_{t}+\varepsilon_{i, t+1}$, where $R_{i, t+1}^{S A}$ is one-month ahead return on industry $i$ in SA, where $R_{U S, t}^{M}$ is the return on the US market in month $t, R_{U S, t}^{M} *$ Dum $t$ is an interaction term of $R_{U S, t}^{M}$ and $\operatorname{Dum}_{t}$, where $\operatorname{Dum}_{t}$ is a dummy variable equal to 0 for the pre-1996 SA market change period and 1 otherwise. *, **, and $* * *$ denote significance at the $10 \%, 5 \%$, and $1 \%$ levels, respectively. Significant regression coefficients are highlighted in bold. Industry names (ind1 to ind30) are described in Table 1. "NA" denotes that there are not enough sample observations for this industry to run a meaningful regression. NeweyWest heteroskedasticity and autocorrelation consistent standard errors are used to compute $t$-statistics. 
Table 4

Predictability of lagged US industry returns on SA industry returns: Pre-and post-1996 periods

\begin{tabular}{|c|c|c|c|c|c|c|c|c|c|}
\hline Portfolio & const & t-stat & $R_{i, t}$ & t-stat & $R_{i, t}^{U S}$ & t-stat & $R_{i, t}^{U S} *$ Dum $_{t}$ & t-stat & $\mathrm{R}^{2}$ \\
\hline ind1 & $0.014 * *$ & $(2.94)$ & -0.050 & $(-0.95)$ & $0.271 * *$ & $(2.76)$ & -0.144 & $(-1.04)$ & 0.008 \\
\hline ind2 & $0.009 *$ & $(1.92)$ & 0.048 & $(0.98)$ & $0.252^{* *}$ & $(2.72)$ & 0.017 & $(0.11)$ & 0.030 \\
\hline ind3 & $0.011^{* *}$ & $(2.16)$ & -0.070 & $(-1.29)$ & $0.275^{* *}$ & (3.06) & -0.012 & $(-0.10)$ & 0.031 \\
\hline ind4 & 0.008 & $(0.85)$ & $-0.142 *$ & $(-1.82)$ & 0.065 & $(0.34)$ & 0.191 & $(0.84)$ & 0.021 \\
\hline ind5 & $0.012 * *$ & $(3.00)$ & -0.015 & $(-0.25)$ & 0.098* & (1.89) & -0.075 & $(-1.05)$ & 0.001 \\
\hline ind6 & $0.010 *$ & $(1.73)$ & 0.059 & $(1.02)$ & -0.319 & $(-1.33)$ & 0.411 & $(1.60)$ & 0.002 \\
\hline ind7 & $0.014 * *$ & $(4.06)$ & -0.054 & $(-1.37)$ & $0.269 * *$ & $(4.26)$ & -0.096 & $(-0.71)$ & 0.020 \\
\hline ind8 & 0.007 & $(0.91)$ & 0.088 & $(0.91)$ & $1.075^{* *}$ & $(4.84)$ & $-1.035^{* *}$ & $(-3.93)$ & 0.008 \\
\hline ind9 & $0.019 * *$ & $(2.50)$ & -0.108 & $(-1.24)$ & -0.169 & $(-0.58)$ & 0.275 & $(0.84)$ & 0.002 \\
\hline ind10 & $0.010 * *$ & (2.94) & 0.012 & $(0.17)$ & 0.231 & (1.59) & -0.135 & $(-0.87)$ & 0.004 \\
\hline ind11 & $0.014 * *$ & (2.76) & -0.007 & $(-0.14)$ & 0.332 & (1.08) & -0.147 & $(-0.46)$ & 0.009 \\
\hline ind12 & $0.012 * *$ & $(4.26)$ & 0.055 & $(1.24)$ & $0.207^{* *} *$ & (2.74) & -0.085 & $(-0.65)$ & 0.018 \\
\hline ind13 & NA & & & & & & & & \\
\hline ind14 & $0.011^{* *}$ & (2.15) & 0.022 & $(0.26)$ & 0.106 & $(0.63)$ & -0.092 & $(-0.49)$ & -0.009 \\
\hline ind15 & $0.016 * *$ & (2.89) & 0.031 & $(0.30)$ & 0.348 & $(1.32)$ & -0.267 & $(-0.94)$ & 0.003 \\
\hline ind 16 & $0.028 * *$ & (3.24) & -0.052 & $(-0.64)$ & -0.094 & $(-0.31)$ & 0.065 & $(0.16)$ & -0.008 \\
\hline ind17 & NA & & & & & & & & \\
\hline ind18 & 0.009 & $(1.46)$ & $0.059 * *$ & $(2.37)$ & 0.212 & $(0.69)$ & -0.177 & $(-0.54)$ & -0.003 \\
\hline ind19 & $0.015^{* *}$ & (2.39) & 0.086 & (1.06) & 0.160 & (1.45) & 0.000 & $(0.00)$ & 0.014 \\
\hline ind20 & 0.004 & $(0.50)$ & -0.028 & $(-0.38)$ & -0.231 & $(-0.94)$ & 0.351 & $(1.30)$ & -0.006 \\
\hline ind 21 & NA & & & & & & & & \\
\hline ind 22 & NA & & & & & & & & \\
\hline ind 23 & $0.015^{* *}$ & $(4.56)$ & -0.015 & $(-0.36)$ & $0.329 * *$ & (2.89) & $-0.293^{* *}$ & $(-2.21)$ & 0.013 \\
\hline ind24 & $0.015 * *$ & $(4.03)$ & 0.059 & $(1.33)$ & $0.362 * *$ & (1.96) & -0.229 & $(-1.16)$ & 0.022 \\
\hline ind25 & $0.014^{* *}$ & $(4.15)$ & -0.004 & $(-0.09)$ & $0.269 * *$ & (3.46) & $-0.295^{* *}$ & $(-3.43)$ & 0.022 \\
\hline ind26 & NA & & & & & & & & \\
\hline ind27 & $0.016^{* *}$ & (3.65) & -0.047 & $(-0.73)$ & -0.103 & $(-1.13)$ & 0.056 & $(0.44)$ & -0.005 \\
\hline ind28 & $0.017 * *$ & (3.92) & -0.039 & $(-0.63)$ & $0.255^{*}$ & (1.88) & -0.087 & $(-0.60)$ & 0.010 \\
\hline ind29 & NA & & & & & & & & \\
\hline Ind30 & $0.009 *$ & $(1.91)$ & -0.034 & $(-0.42)$ & 0.096 & $(0.49)$ & -0.055 & $(-0.27)$ & -0.007 \\
\hline
\end{tabular}

Notes: Regression equation: $R_{i, t+1}^{S A}=\alpha_{i}+\beta_{i} R_{i, t}^{S A}+\gamma_{i} R_{i, t}^{U S}+\kappa_{i} R_{i, t}^{U S} * D u m_{t}+\varepsilon_{i, t+1}$, where $R_{i, t+1}^{S A}$ is one-month ahead return on industry $i$ in SA, and $R_{i, t}^{U S}$ is lagged US industry returns that are corresponding and common to the SA industry portfolios. $R_{i, t}^{U S} * D_{t}$ is an interaction term of $R_{i, t}^{U S}$ and Dum $m_{t}$, where $\operatorname{Dum}_{t}$ is a dummy variable equal to 0 for the pre-1996 market change period and 1 otherwise. *, **, and *** denote significance at the $10 \%, 5 \%$, and $1 \%$ levels, respectively. Significant regression coefficients are highlighted in bold. Industry names (ind1 to ind30) are described in Table 1. "NA" denotes that there are not enough sample observations for this industry to run a meaningful regression. Newey-West heteroskedasticity and autocorrelation consistent standard errors are used to compute $t$-statistics. 